\title{
Design of a Short/Open-Ended Slot Antenna with Capacitive Coupling Feed Strips for Hepta-Band Mobile Application
}

\author{
Kyoseung Keum $\cdot$ Haiyan Piao $\cdot$ Jaehoon Choi*
}

\begin{abstract}
In this paper, a planar printed hybrid short/open-ended slot antenna with capacitive coupling feed strips is proposed for hepta-band mobile applications. The proposed antenna is comprised of a slotted ground plane on the top plane and two capacitive coupling feed strips with a chip inductor on the bottom plane. At the low frequency band, the short-ended long slot fed by strip 1 generates its halfwavelength resonance mode, whereas the $\mathrm{T}$-shaped open ended slot fed by strip 2 generates its quarter-wavelength resonance mode for the high frequency band. The antenna provides a wide bandwidth covering GSM850/GSM900/DCS/PCS/UMTS/LTE2300/ LTE2500 operation bands. Moreover, the antenna occupies a small volume of $15 \mathrm{~mm} \times 50 \mathrm{~mm} \times 1 \mathrm{~mm}$. The operating principle of the proposed antenna and the simulation/measurement results are presented and discussed.
\end{abstract}

Key Words: Capacitive Feed, Chip Inductor, Hepta-Band Mobile Antenna, Slot Antenna.

\section{INTRODUCTION}

With the rapid development of mobile communication technology and diversified demand of mobile users, multi-band antennas become essential for mobile communication systems [1]. In some mobile applications, it is desirable to integrate heptaband systems, such as GSM850/GSM900 bands in the lower band and DCS/PCS/UMTS/LTE2300/LTE2500 bands in the upper band, into a single mobile device. However, it is a big challenge for a single mobile device to accommodate a heptaband antenna due to the space limitation of the printed circuit board (PCB). For this reason, a mobile antenna should be designed in low profile planar structure and in compact size without deteriorating the performance. Slot antenna, with the advantages of low-profile, simple structure, and easy integration with other devices, is a good candidate for the design of multiband antennas $[2,3]$. However, the slot antenna has difficulty covering the low-frequency bands by a single resonance [4]. To overcome this problem, various researches using multi-resonance at the lower frequency band have been studied [5-9]. In these studies, multi-resonance characteristic was achieved by using capacitive coupling feed. However, these antennas have narrow bandwidth at high-frequency bands.

In this paper, we propose a compact slot antenna covering GSM850 (824-894 MHz), GSM900 (880-960 MHz), DCS (1,710-1,880 MHz), PCS (1,850-1,990 MHz), UMTS $(1,920$ $-2,170 \mathrm{MHz}), \mathrm{LTE} 2300(2,305-2,400 \mathrm{MHz})$, and LTE2500 $(2,500-2,690 \mathrm{MHz})$ bands. The proposed antenna consists of two capacitive coupling feed strips, a chip inductor, a shortended slot, and an inverted T-shaped open-ended slot. The

Manuscript received August 11, 2017 ; Revised November 28, 2017 ; Accepted December 24, 2017. (ID No. 20170811-038J)

Department of Electronics and Computer Engineering, Hanyang University, Seoul, Korea.

"Corresponding Author: Jaehoon Choi (e-mail: choijh@hanyang.ac.kr)

This is an Open-Access article distributed under the terms of the Creative Commons Attribution Non-Commercial License (http://creativecommons.org/licenses/by-nc/4.0) which permits unrestricted non-commercial use, distribution, and reproduction in any medium, provided the original work is properly cited.

(c) Copyright The Korean Institute of Electromagnetic Engineering and Science. All Rights Reserved. 
proposed antenna is simulated by ANSYS High-Frequency Structure Simulator (HFSS; ANSYS Inc., Canonsburg, PA, USA).

\section{ANTENNA DESIGN}

The configuration of the proposed antenna for hepta-band mobile application is shown in Fig. 1. The antenna is designed on a FR-4 $\left(\varepsilon_{r}=4.4, \tan \delta=0.02\right)$ substrate with a thickness of 1 $\mathrm{mm}$. The dimension of FR-4 substrates is $50 \mathrm{~mm} \times 115 \mathrm{~mm}$ $\times 1 \mathrm{~mm}$, and the antenna with a dimension of $15 \mathrm{~mm} \times 50$ $\mathrm{mm} \times 1 \mathrm{~mm}$ is located at the upper side of the substrate. The short-ended slot forms a loop along the edge of the antenna and the T-shaped slot is placed at the upper edge of the ground plane. Coupling feed strip is comprised of strip 1 and strip 2. The chip inductor is connected in series with the strip 1 and strip 2. The short-ended slot and T-shaped slot, are excited by strip 1 and strip 2, respectively. By electromagnetic coupling between the short-ended slot and strip 1, dual resonances are generated to cover GSM850/900 bands. A wideband characteristic at the high-frequency band is achieved by the combination of the harmonic resonance of the short-ended slot and the resonances due to the $\mathrm{T}$-shaped slot and the strip 2. Table 1 shows

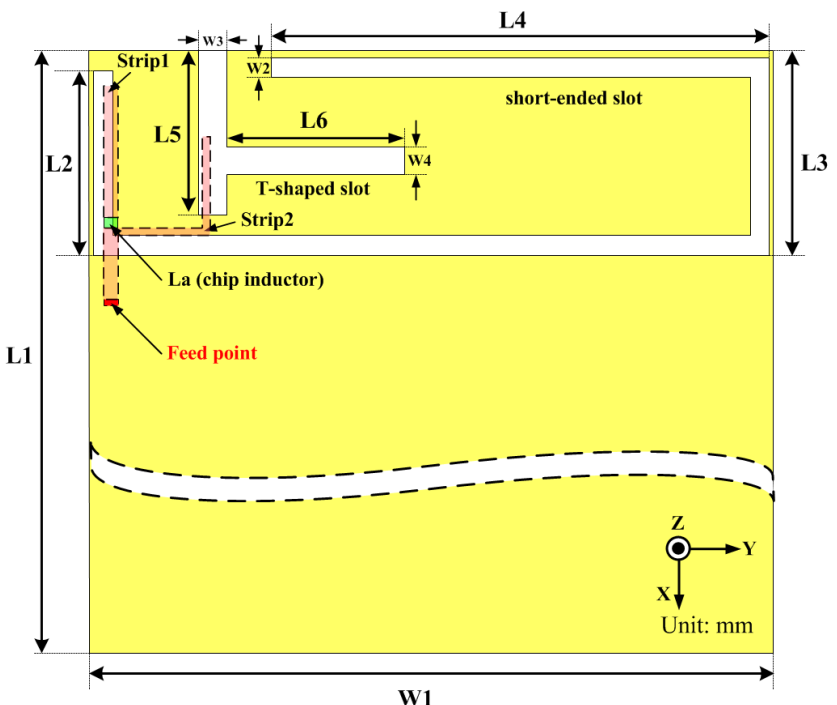

Fig. 1. The geometry of the proposed antenna.

Table 1. Design parameters of the proposed antenna

\begin{tabular}{cc|cc}
\hline Parameter & Value & Parameter & Value \\
\hline$L_{1}$ & $115 \mathrm{~mm}$ & $W_{1}$ & $50 \mathrm{~mm}$ \\
$L_{2}$ & $13.5 \mathrm{~mm}$ & $W_{2}$ & $1.5 \mathrm{~mm}$ \\
$L_{3}$ & $15 \mathrm{~mm}$ & $W_{3}$ & $2 \mathrm{~mm}$ \\
$L_{4}$ & $36.5 \mathrm{~mm}$ & $W_{4}$ & $2 \mathrm{~mm}$ \\
$L_{5}$ & $12 \mathrm{~mm}$ & $L_{a}$ & $22 \mathrm{nH}$ \\
$L_{6}$ & $13 \mathrm{~mm}$ & - & - \\
\hline
\end{tabular}

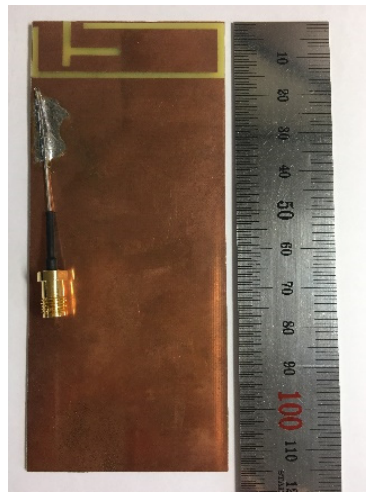

(a)

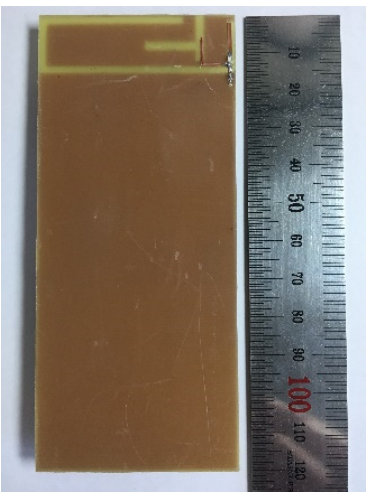

(b)
Fig. 2. Prototyped antenna: (a) top view and (b) bottom view.

the design parameters of the proposed antenna and the fabricated antenna is shown in Fig. 2. Fig. 2(a) shows the slots of the ground plane and the feed cable and Fig. 2(b) shows the strips and chip inductor.

\section{ANTENNA ANALYSIS}

Fig. 1 shows the various design parameters mostly affecting the antenna performances. In order to analyze and verify the operation principle of the proposed antenna, the parametric study has been conducted.

Fig. 3(a) shows the simulated reflection coefficient when the length of the top slot $\left(L_{4}\right)$ varies from $34.5 \mathrm{~mm}$ to $38.5 \mathrm{~mm}$. It can be seen that as the length of $L_{4}$ increases the whole frequency band is shifted to the lower frequency side. In particular, $L_{4}$ largely affects the reflection coefficient characteristics at GSM900, DCS and LTE bands. These frequencies correspond to the half-wave resonance of the short-ended slot and its second and third harmonic resonances, respectively. The optimal length of $L_{4}$ is chosen as $36.5 \mathrm{~mm}$. Fig. 3(b) shows the simulated reflection coefficient when the length of the T-shaped slot $\left(L_{5}\right)$ changes from $11.5 \mathrm{~mm}$ to $12.5 \mathrm{~mm}$. It is observed that the upper frequency band is shifted to lower frequency as the length of $L_{5}$ increases. In particular, $L_{5}$ largely affects the performance at GSM900, UMTS, LTE bands. The optimal length of $L_{5}$, satisfying the $-6 \mathrm{~dB}$ reflection coefficient is $12 \mathrm{~mm}$. Fig. 3(c) shows the simulated reflection coefficient when the length of the T-shaped slot $\left(L_{6}\right)$ is changing from $12 \mathrm{~mm}$ to $14 \mathrm{~mm}$. It is shown that as the length of $L_{6}$ increases, the upper frequency band is shifted to the low frequency side. In particular, the GSM900, UMTS, LTE bands are affected critically by the change of $L_{6}$. When $L_{6}$ becomes $14 \mathrm{~mm}$, the antenna has wider $-6 \mathrm{~dB}$ reflection coefficient bandwidth than that of $13 \mathrm{~mm}$ in the high frequency band. However, since the $-6 \mathrm{~dB}$ reflection coefficient in the GSM and PCS bands is satisfied marginally, the length of $L_{6}$ is set to $13 \mathrm{~mm}$. Fig. 4 shows the simulated 


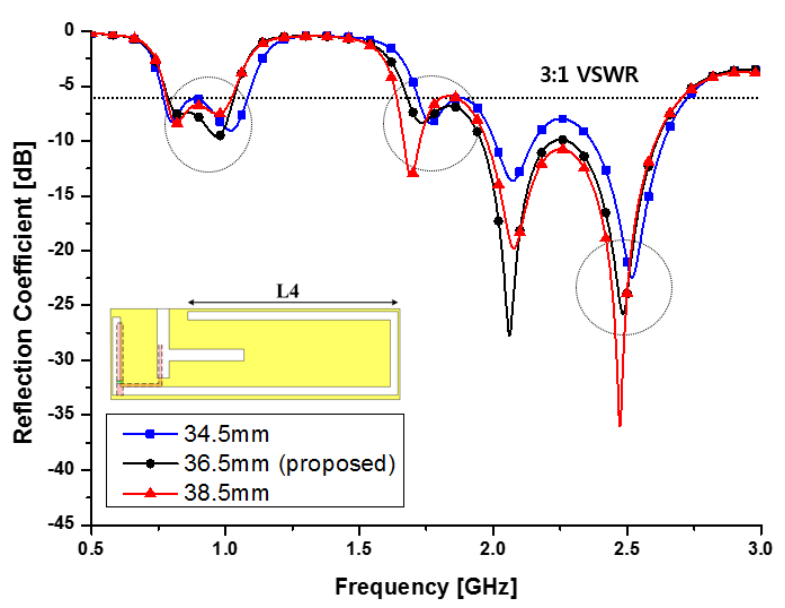

(a)

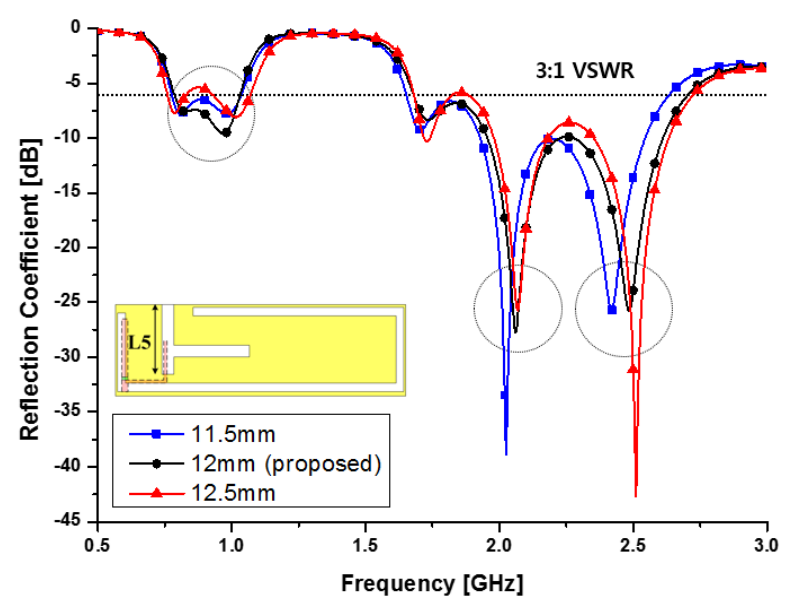

(b)

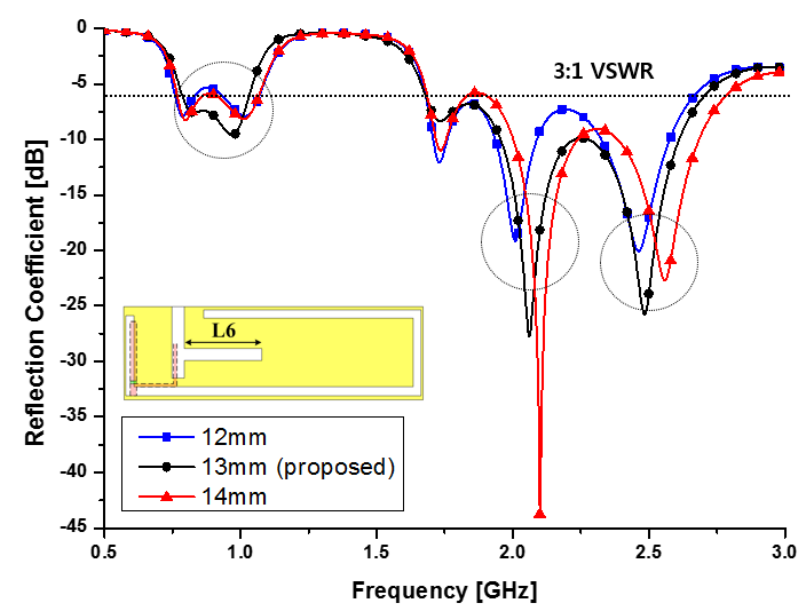

(c)

Fig. 3. The simulated reflection coefficient with different values of $L_{4}$ (a), $L_{5}(\mathrm{~b})$, and $L_{6}$ (c).

reflection coefficient when the values of the chip inductor $L_{a}$ are $18 \mathrm{nH}, 22 \mathrm{nH}$, and $27 \mathrm{nH}$. The change of the inductor value affects the reflection coefficient characteristic in the lower frequency GSM band more critically than in the upper frequency bands. It can be seen that as the inductor value increases, the resonance occurs at the low side of the lower frequency band,

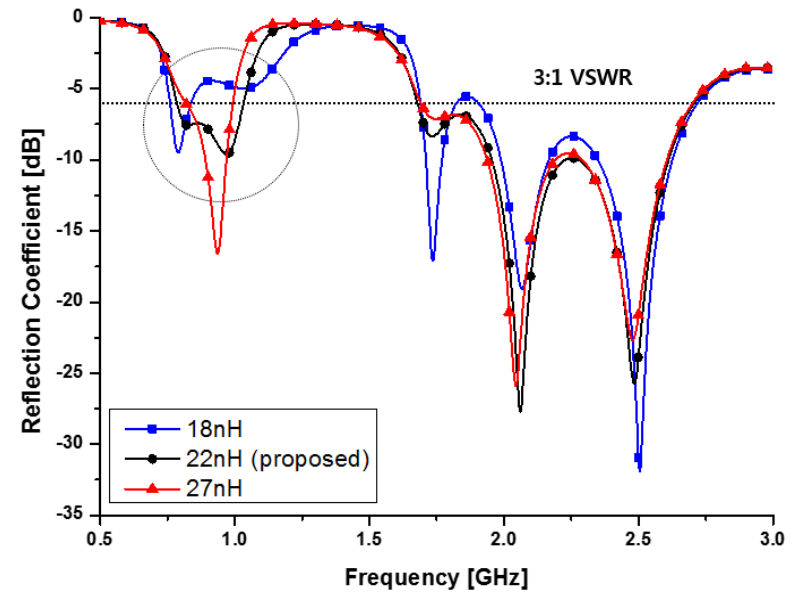

Fig. 4. Simulated reflection coefficient with different chip inductor values of $L_{a}$

and when the inductor value decreases, the resonance occurs at the high side of the lower band. The $-6 \mathrm{~dB}$ reflection coefficient at the GSM band is satisfied when the inductor value is $22 \mathrm{nH}$.

Fig. 5 shows the surface current distributions on the proposed antenna. At lower bands, the surface current around the shortended slot is strongly excited by the capacitive coupling due to feed strip 1. This current distribution shows that the shortended slot with the strip 1 generates the half-wavelength resonance $[10,11]$ and its harmonic modes at the vicinity of 0.85 , 1.73, and $2.50 \mathrm{GHz}$. At the upper bands, the intensity of the surface current distribution around the T-shaped slot becomes relatively stronger than that at the lower-frequency band. The current distribution shows that the T-shaped open-ended slot with the strip 2 generates the quarter-wavelength resonance mode [10] at the vicinity of $2.06 \mathrm{GHz}$ and $2.50 \mathrm{GHz}$.

\section{SiMULATION AND MEASUREMENT RESULTS}

Fig. 6 shows the simulated and measured reflection coeffi-

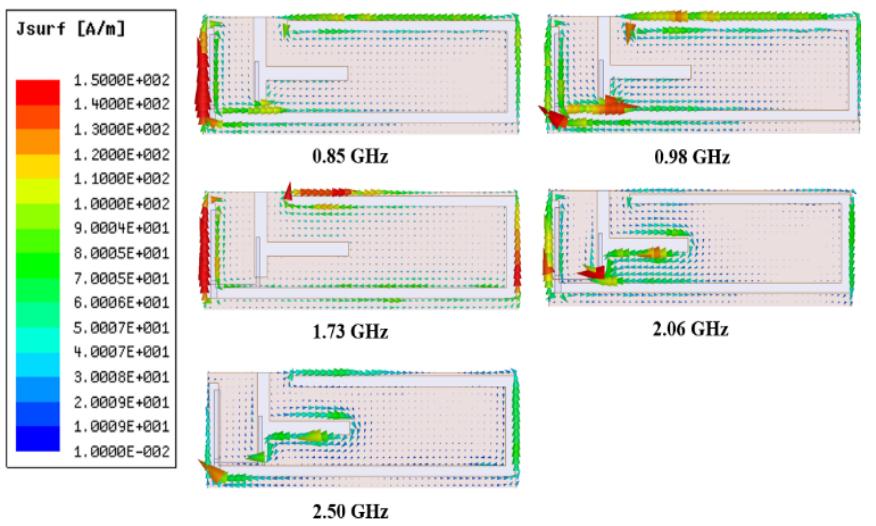

Fig. 5. The simulated surface current distributions on the proposed antenna. 


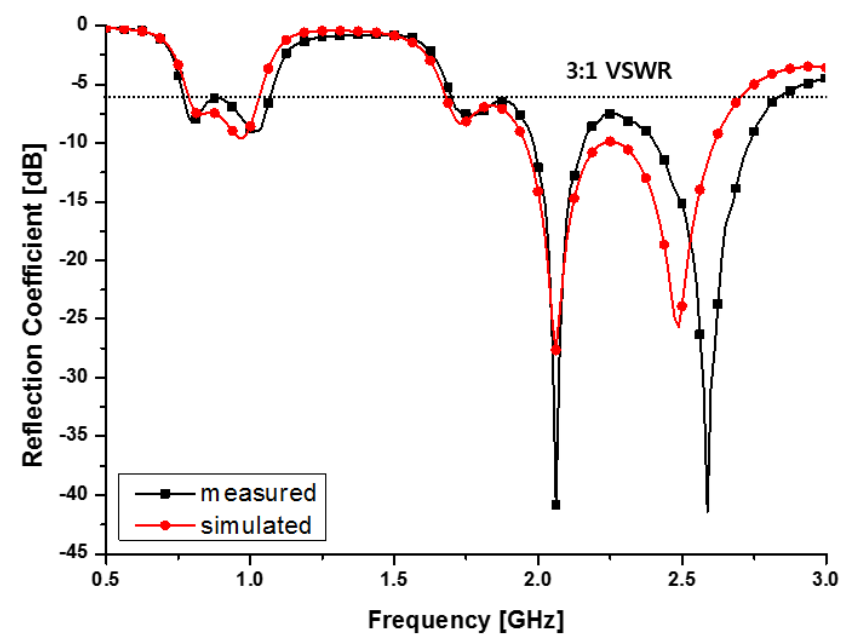

Fig. 6. Simulated and measured reflection coefficient of the proposed antenna.
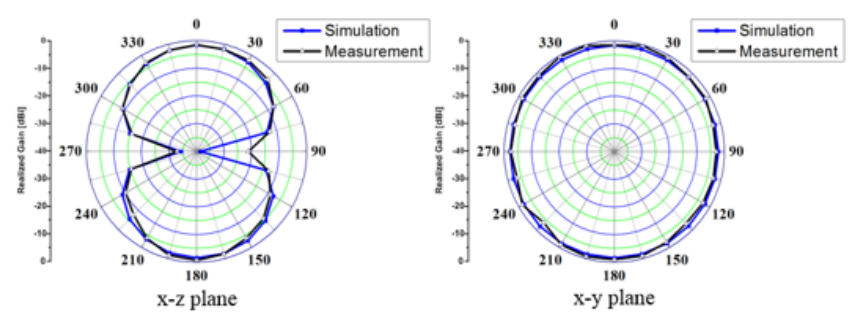

(a)
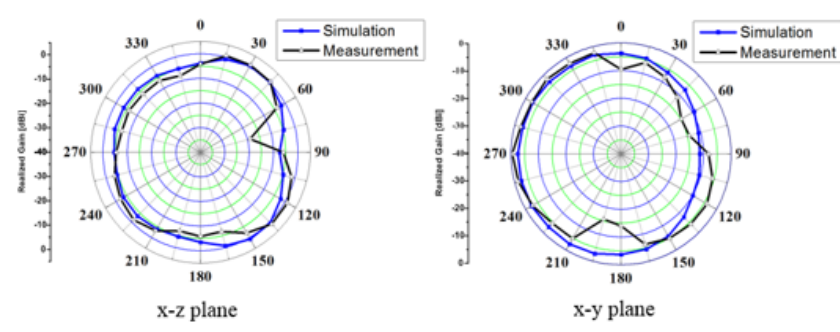

(c)
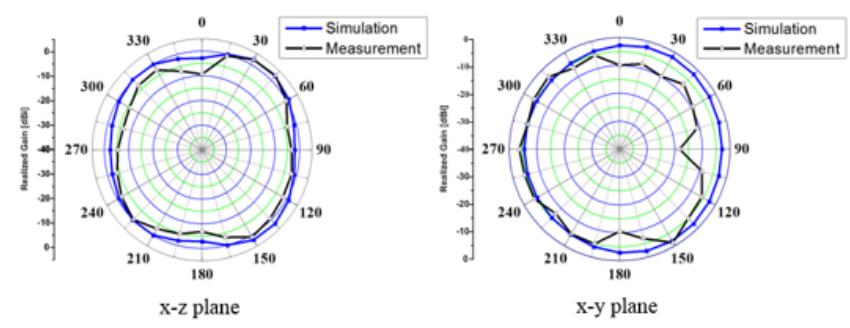

(e)

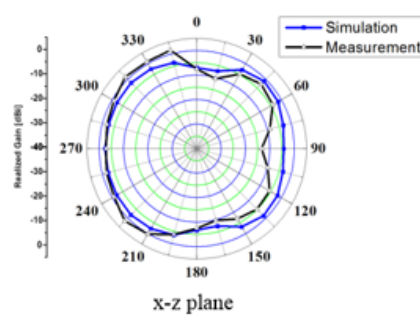

cients of the proposed antenna. The $-6 \mathrm{~dB}$ reflection coefficient bandwidths are $260 \mathrm{MHz}(0.77-1.03 \mathrm{GHz})$ at the lower band and $1,040 \mathrm{MHz}(1.66-2.70 \mathrm{GHz})$ at the upper band. The bandwidth of the proposed antenna is wide enough to cover the desired hepta-band. The measured 2D radiation patterns of the proposed antenna are shown in Fig. 7. The 2D radiation patterns were measured at the center frequency of each band. At low frequencies, with the center frequencies of the GSM850 and GSM900 bands at $0.86 \mathrm{GHz}$ and $0.92 \mathrm{GHz}$, respectively, dipole-like radiation patterns can be observed in the $x-z$ plane. In the $x-y$ plane, the radiation patterns are omni-directional. At high frequencies, with the center frequencies of the DCS, PCS, UMTS, LTE2300, and LTE2500 bands at 1.80, 1.92, 2.05, 2.35 , and $2.60 \mathrm{GHz}$, respectively, the proposed antenna has quasi-omnidirectional radiation patterns. Fig. 8 illustrates the
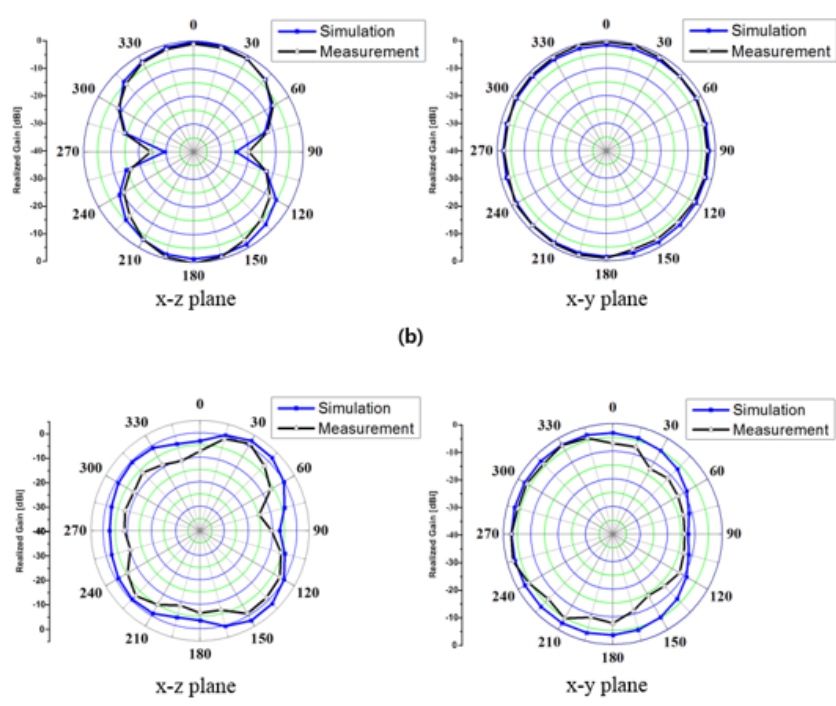

(d)
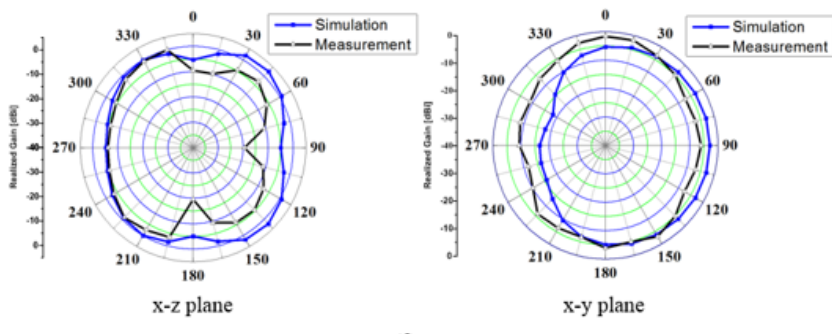

(f)

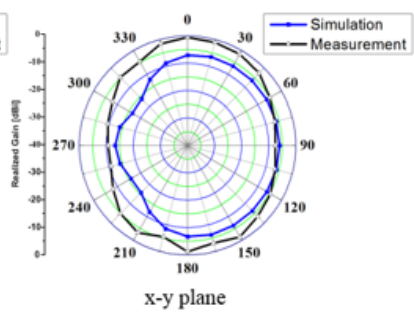

Fig. 7. Simulated and measured radiation patterns of the proposed antenna at (a) $0.86 \mathrm{GHz}$, (b) $0.92 \mathrm{GHz}$, (c) $1.80 \mathrm{GHz}$, (d) $1.92 \mathrm{GHz}$, (e) 2.05 $\mathrm{GHz}$, (f) $2.35 \mathrm{GHz}$, and (g) $2.60 \mathrm{GHz}$. 


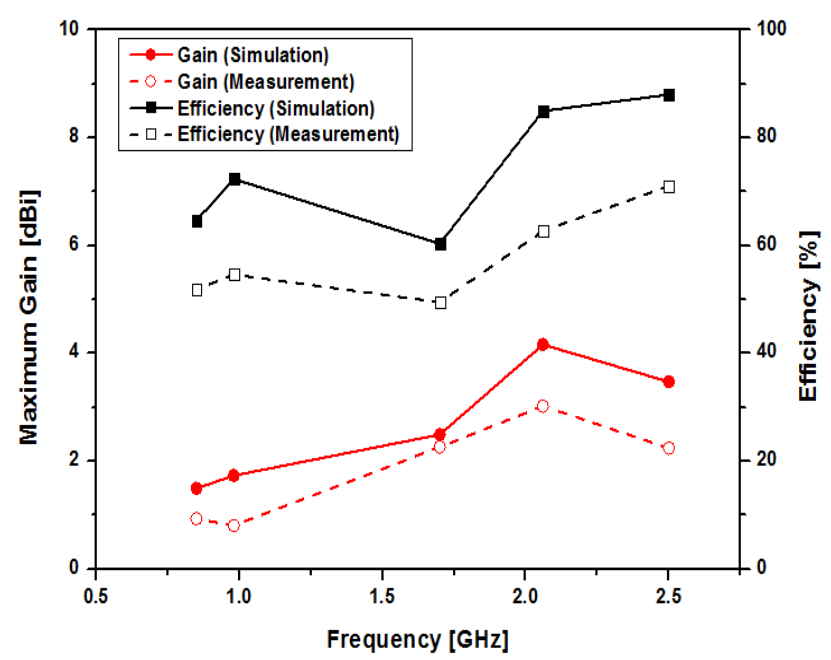

Fig. 8. Simulated and measured efficiencies and maximum gains of the proposed antenna.

simulated and measured efficiencies and maximum gains of the proposed antenna. The measured efficiencies and maximum gains are $51.8 \%$ and $0.93 \mathrm{dBi}, 54.6 \%$ and $0.8 \mathrm{dBi}, 49.5 \%$ and $2.26 \mathrm{dBi}, 62.7 \%$ and $3.02 \mathrm{dBi}, 71.1 \%$ and $2.24 \mathrm{dBi}$, at 0.85 , $0.98,1.73,2.06$, and $2.50 \mathrm{GHz}$, respectively. As shown in Fig. 8 , the measured efficiencies and maximum gains are substantially lower than the simulated results. This is mainly due to the metal surface roughness of the FR4 substrate which is not accounted for in the simulation [12]. Moreover, the percent error of the chip inductor and fabrication errors of capacitive coupling strips lead to the loss of gain.

\section{CONCLUSION}

In this paper, a hepta-band planar printed hybrid short/openended slot antenna with capacitive coupling feed strips is proposed. By properly choosing the lengths of feed strip 1 and strip 2 and the value of chip inductor, the proposed antenna has a wide bandwidth of $260 \mathrm{MHz}$ covering GSM850 and GSM900 bands in the lower frequency band and $1,040 \mathrm{MHz}$ covering DCS, PCS, UMTS, LTE2300, and LTE2500 bands in the upper frequency band. The geometrical parameters of the shortended slot and the feeding strip 1 are mainly affecting the antenna performances at GSM900, DCS, and LTE bands and those of open-ended T-shaped slot and the feeding strip 2 determines the antenna characteristics at GSM900, UMTS, and LTE bands. Along with the wide bandwidth, the antenna has good radiation properties desired for mobile communication applications.

This work was supported by the National Research Foundation of Korea (NRF) grant funded by the Korea government (MSIP) (No. 2017R1A2B4002811).

\section{REFERENCES}

[1] Y. Hong, Y. Zhang, W. Hong, and K. Wu, "Wideband millimeter-wave SIW cavity backed patch antenna fed by substrate integrated coaxial line," in Proceedings of 2015 IEEE International Wireless Symposium (IWS), Shenzhen, China, 2015, pp. 1-4.

[2] Y. F. Cao, S. W. Cheung, and T. I. Yuk, "A multiband slot antenna for GPS/WiMAX/WLAN systems," IEEE Transactions on Antennas and Propagation, vol. 63, no. 3, pp. 952958, 2015.

[3] X. Zhao and J. Choi, "Compact reconfigurable wideband inverted-F antenna for LTE MIMO mobile applications," IEICE Transactions on Communications, vol. 97, no. 9, pp. 1921-1927, 2014.

[4] C. Deng, Y. Li, Z. Zhang, and Z. Feng, "Planar printed multi-resonant antenna for octa-band WWAN/LTE mobile handset," IEEE Antennas and Wireless Propagation Letters, vol. 14, pp. 1734-1737, 2015.

[5] S. L. Zuo, Z. Y. Zhang, and J. J. Xie, "Design of dualmonopole slots antenna integrated with monopole strip for wireless wide area network mobile handset," IET Microwaves Antennas and Propagation, vol. 8, no. 3, pp. 194-199, 2013.

[6] C. K. Hsu and S. J. Chung, "Compact multiband antenna for handsets with a conducting edge," IEEE Transactions on Antennas and Propagation, vol. 63, no. 11, pp. 5102-5107, 2015.

[7] F. H. Chu and K. L. Wong, "Simple folded monopole slot antenna for penta-band clamshell mobile phone application," IEEE Transactions on Antennas and Propagation, vol. 57, no. 11, pp. 3680-3684, 2009.

[8] P. W. Lin and K. L. Wong, "Simple monopole slot antenna for WWAN/LTE handset application," in Proceedings of 2011 Asia-Pacific Microwave Conference (APMC), Melbourne, Australia, 2011, pp. 829-832.

[9] C. H. Wu and K. L. Wong, "Hexa-band internal printed slot antenna for mobile phone application," Microwave and Optical Technology Letters, vol. 50, no. 1, pp. 35-38, 2008.

[10] K. L. Wong and P. W. Lin, "Simple printed monopole slot antenna for WWAN mobile handset," in Proceedings of 2011 International Workshop on Antenna Technology (Iwat), Lisbon, Portugal, 2010, pp. 186-189.

[11] B. Yuan, Y. Cao, and G. Wang, "A miniaturized printed slot antenna for six-band operation of mobile handsets," IEEE Antennas and Wireless Propagation Letters, vol. 10, pp. 854-857, 2011.

[12] T. Zhang, Y. Zhang, W. Hong, and K. Wu, "Wideband millimeter-wave SIW cavity backed patch antenna fed by substrate integrated coaxial line," in Proceedings of 2015 
IEEE International Wireless Symposium (IWS), Shenzhen,

\section{Kyoseung Keum}

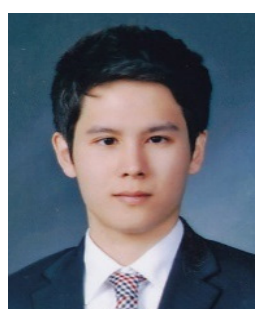

received his B.S. in Information and Communication Engineering from Soonchunhyang University in Asan, Korea, in 2015. He is currently working toward a combined master's and $\mathrm{Ph} . \mathrm{D}$. degree in the Department of Electronics and Computer Engineering at Hanyang University in Seoul, Korea. His research interest focuses on various antenna designs, mainly compact multi-band antennas for mobile wireless communication applications.
China, 2015, pp. 1-4.

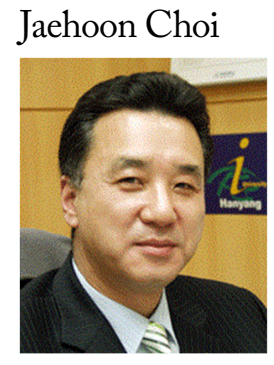

received his B.S. from Hanyang University in Korea, and his M.S. and Ph.D. degrees from Ohio State University in Ohio in 1980, 1986, and 1989, respectively. From 1989 to 1991, he served as a research analyst at the Telecommunication Research Center at Arizona State University in Tempe, Arizona. He worked for Korea Telecom as a team leader of the Satellite Communication Division from 1991 to 1995. Since 1995, he has been a professor in the Department of Electronics and Computer Engineering at Hanyang University in Korea. He has published more than 250 refereed journal articles and numerous conference proceedings. He also holds over 80 patents. His research interests include antennas, microwave circuit design, and electromagnetic compatibility. Currently, his research is mainly focused on the design of compact multiband antennas for mobile wireless communication and antennas for biomedical applications.
Haiyan Piao

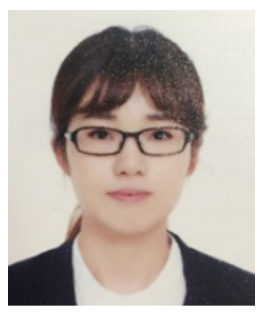

received her B.S. in telecommunication engineering from Yanbian University in Yanji, China, in 2013. From 2013 to 2015, she served as an information technology researcher at China Telecom. She is currently working toward a master's degree in the Department of Electronics and Computer Engineering at Hanyang University in Seoul, Korea. Her research interest focuses on various antenna designs, mainly compact multi-band antennas for mobile wireless communication applications. 